\title{
Dendritic cells produce TSLP that limits the differentiation of Th17 cells, fosters Treg development, and protects against colitis
}

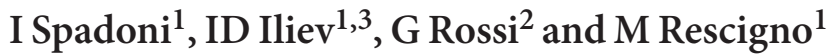

Thymic stromal lymphopoietin (TSLP) is produced by epithelial cells and keratinocytes, and is involved in immune homeostasis or inflammation. The mechanism through which TSLP regulates intestinal inflammation is unclear. Here, we report that mouse dendritic cells (DCs) express TSLP both in vitro and in vivo in response to Toll-like receptor ligation in a MyD88-dependent fashion. TSLP is produced by the $\mathrm{CD}_{103^{+}}$subset of tolerogenic gut DCs and is downregulated during experimental colitis. TSLP produced by DCs acts directly on T cells by reducing their capacity to produce interleukin (IL)-17 and fostering the development of Foxp3 ${ }^{+} \mathrm{T}$ cells. Consistently, TSLP protects against colitis development through a direct action on T cells, as adoptive transfer of naïve T cells from TSLPR ${ }^{-1-}$ to SCID mice results in a more severe colitis, with increased frequency of IL-17-producing T cells and inflammatory cytokines. Hence, we describe a new anti-inflammatory role of TSLP in the gut.

\section{INTRODUCTION}

Thymic stromal lymphopoietin (TSLP) is a cytokine initially isolated from a mouse thymic stromal cell line ${ }^{1}$ and described to be a lymphocyte growth factor. ${ }^{2}$ TSLP has been shown to be produced also by keratinocytes and epithelial cells ${ }^{3}$ in response to several stimuli, including bacteria, parasites, and inflammatory cytokines, via a nuclear factor (NF)-kb-dependent pathway. ${ }^{4,5}$ TSLP levels are increased at sites of inflammation and have been shown to correlate with several pathologies, including atopic dermatitis, allergy, asthma, and recently also cancer. ${ }^{6-10}$ Similarly, overexpression of TSLP in keratinocytes or lung epithelial cells in the mouse has been correlated with allergic skin reactions and asthma, respectively. ${ }^{11-13}$

TSLP signals via its heterodimeric receptor composed by a TSLP receptor (TSLPR) chain (that is closely related to the common $\gamma$-chain) and the interleukin (IL)-7R $\alpha$-chain. ${ }^{14}$ Studies on TSLPR-deficient mice have shown that TSLPR expression on $\mathrm{CD}^{+} \mathrm{T}$ cells is required for the differentiation and pathological effects of Th2T cells. ${ }^{2,12,13}$ A direct effect of TSLP on murine $\mathrm{T}$ cells was demonstrated in vitro as $\mathrm{CD} 4^{+} \mathrm{T}$ cells responded to TSLP by inducing STAT5 phosphorylation, GATA3 expression, and Th2 cytokine production. ${ }^{15}$ The role of TSLPR in human
$\mathrm{T}$ cells is still debated, as naïve $\mathrm{CD} 4^{+} \mathrm{T}$ cells display very little expression of TSLPR although they can upregulate it during activation but not at levels similar to those expressed by dendritic cells (DCs). ${ }^{16,17}$ In addition, TSLP does not directly induce the development of Th2 T cells in the human system. ${ }^{16}$

TSLP is produced also by mouse and human resting intestinal epithelial cells ${ }^{18-20}$ and its expression in vitro has been shown to be regulated by commensal or probiotic bacteria. ${ }^{21,22}$ TSLP expression by intestinal epithelial cells is fundamental for the inhibition of IL- 12 production by DCs both in the mouse and in the human system. ${ }^{19,20}$ In addition, TSLP is required for the generation of tolerogenic DCs capable of inducing T-regulatory cells expressing Foxp3 in the human but not in the mouse system. ${ }^{23-25}$ Further, TSLP can induce the expression of secretory leukocyte peptidase inhibitor, an endogenous inhibitor of neutrophil elastase. ${ }^{26}$ Hence, besides pro-inflammatory activity, TSLP seems to have a role in the physiological function of the gut by promoting a noninflammatory and tolerogenic environment. Indeed, we have shown that epithelial cells from a vast majority of Crohn's disease patients fail to promote tolerogenic DCs and this correlates with a reduced expression of TSLP. ${ }^{20,24}$ It has been shown that mice deficient for TSLPR display an increased

${ }^{1}$ Department of Experimental Oncology, European Institute of Oncology, Milan, Italy. ${ }^{2}$ Scuola di Scienze Mediche Veterinarie, Università degli Studi di Camerino, Macerata (MC), Italy. ${ }^{3}$ Present address: Department of Inflammatory Bowel Disease, Cedars-Sinai Medical Center, Los Angeles, CA 90048, USA.Correspondence: M Rescigno (maria.rescigno@ifom-ieo-campus.it)

Received 13 May 2011; accepted 21 November 2011; published online 11 January 2012. doi:10.1038/mi.2011.64 
susceptibility to Trichuris muris infection and experimental colitis; ${ }^{18}$ however, the role of TSLP in controlling intestinal inflammation in the mouse system remains elusive, particularly in light of the recent finding that DCs also can produce TSLP. ${ }^{27}$

Here, we confirm that mouse DCs express TSLP both in vitro and in vivo in response to Toll-like receptor (TLR) ligation in a MyD88-dependent fashion. We show that DC-derived TSLP limits Th17 polarization and fosters Foxp $3^{+}$Treg development. Consistently, adoptive transfer of naïve T cells from TSLPR ${ }^{-/-}$ to SCID mice results in a more severe pathology.

\section{RESULTS}

\section{TSLP is required to protect the gut from inflammation}

We recently described that while in the human system TSLP is involved in controlling the differentiation of gut tolerogenic DCs, ${ }^{24}$ in the mouse system epithelial cell-derived TSLP is dispensable to drive $\mathrm{CD} 103^{+}$tolerogenic DCs. ${ }^{23}$ Hence, whether TSLP has a role in intestinal inflammation in the mouse system remains elusive. We addressed this issue by testing the susceptibility of TSLPR ${ }^{-1-}$ to experimental colitis. TSLPR ${ }^{-1-}$ and control mice were treated for 7 days with $5 \%$ dextran sodium sulfate (DSS) and were then followed for the development of colitis and cytokine production in the intestine. Progression of the disease was monitored by body weight loss, diarrhea, and the appearance of blood in the feces. As shown in Figure 1, TSLPR ${ }^{-1-}$ mice displayed an increased susceptibility to colitis, as attested by a more pronounced weight loss (Figure 1a) and disease activity index (Figure 1b). Histopathological analysis confirmed the increased severity of the disease in $\mathrm{TSLPR}^{-/-}$mice as they displayed an altered histology, including focal crypt epithelial destruction and extensive areas of epithelial hyperplasia associated with mononuclear infiltrates (Figure 1c). The colons of mice also displayed an increased frequency of $\mathrm{CD}^{+}$interferon (IFN)- $\gamma^{+}$and IL-17+ T cells (Figure 1d, Supplementary Figure S1), and statistically significant higher levels of pro-inflammatory cytokines, such as IFN- $\gamma$ and tumor necrosis factor- $\alpha$ (Figure 1e). Surprisingly, we also found an increase of the Th2 cytokine IL-13 (Figure 1e). IL-17 was upregulated but the difference did not reach statistical significance (Figure 1e). Hence, TSLP signaling is required to preserve intestinal homeostasis; however, as we have shown that TSLP is not involved in driving tolerogenic DCs, the mechanism remains elusive.

\section{TSLPR expression on T cells is required to protect against colitis}

As shown above, TSLPR ${ }^{-1-}$ mice show an increased susceptibility to DSS colitis. As TSLP is not involved in driving tolerogenic DCs, ${ }^{23}$ we postulated that it may be due to a direct effect of TSLP on $\mathrm{T}$ cells as TSLPR expression on $\mathrm{T}$ cells is required for some pathological effects of TSLP.,12,13 To evaluate this possibility, we used an adoptive T-cell transfer model of colitis by reconstituting SCID mice with naïve $\mathrm{CD} 4{ }^{+} \mathrm{CD} 25^{-} \mathrm{CD} 45 \mathrm{RB}^{\text {hi }} \mathrm{T}$ cells isolated either from wild-type (WT) or from TSLPR ${ }^{-1-}$ mice. In this way the only cells lacking TSLPR would be T cells. Mice were weekly monitored for signs of colitis and nearly 2 months later they were killed. Colons were collected and analyzed for lymphocyte infiltrates and expression of inflammatory cytokines. We found that mice receiving TSLPR ${ }^{-1}-\mathrm{T}$ cells displayed a more severe colitis as assessed by the histopathological analysis of the colons (Figure 2a). Tissue sections from TSLPR ${ }^{-/-}$mice exhibited increased inflammatory cell infiltrate and extensive areas of epithelial hyperplasia (Figure 2a). SCID mice adoptively transferred with TSLPR $^{-1-}$ T cells displayed a similar amount of IFN- $\gamma$-producing T cells but a marked increase of IL-17-producing T cells (Figure 2b, Supplementary Figure S2). Similarly, the expression of inflammatory cytokines as assessed by quantitative PCR of colon homogenates was drastically increased in mice receiving TSLPR ${ }^{-1-}$ T cells (Figure $2 \mathrm{c}$ ). In particular, we observed a statistically significant increase in $i l 17 a, i l 4, i l 6$, and cox2 gene expression, but not in if $n-\gamma$ where the increase did not reach statistical significance. This observation suggests that TSLP is involved in controlling IL-17 production by T cells and proposes a new anti-inflammatory role of TSLP on T cells.

\section{Mouse DCs express TSLP}

Having shown that TSLP has a protective role against colitis through a direct action on T cells, we wondered whether also DCs expressed TSLP and this could be the source of T-cell-acting TSLP. We evaluated the expression of TSLP by bone marrow-derived DCs (BMDCs) after maturation induced by several TLR ligands. We found that BMDCs expressed TSLP messenger RNA and that TLR triggering resulted in TSLP upregulation (Figure 3a). We found that lipopolysaccharide (LPS) was the most powerful inducer of TSLP expression, hence we used this stimulus for subsequent experiments. LPS can trigger two intracellular pathways, one is dependent on the adaptor protein MyD88 and the other on TRIF. ${ }^{28}$ Hence, we then evaluated whether the induction of TSLP expression by LPS was dependent on MyD88 by using BMDCs from MyD88 ${ }^{-1-}$ mice. We found that lack of MyD88 signaling abrogated LPS-induced TSLP expression (Figure $\mathbf{3 b}$ ). To assess whether TSLP protein was expressed, BMDCs were treated or not with LPS and lysed. TSLP protein was immunoprecipitated and analyzed by western blot. Paralleling the quantitative PCR results, we detected enhanced TSLP production in LPS-treated BMDCs (Figure 3c). We then evaluated whether DCs expressed TSLP also in vivo. Mice were injected intravenously with LPS and after $24 \mathrm{~h} \mathrm{CD11c^{+ }}$ DCs were isolated from spleens. TSLP was detected in splenic DCs only after LPS treatment (Figure 3c). Hence, in vitro and in vivo, DCs express TSLP after LPS stimulation via a MyD88-dependent pathway. This is likely occurring via LPS-induced NF-kB activation as an active NF-kB binding site has been described on the TSLP gene promoter. ${ }^{4}$

\section{DC-derived TSLP controls Th17 and Treg cell development}

It has been described that TSLP has an important role in driving Th2-promoting DCs by inhibiting IL-12 production, both in the mouse and human system. ${ }^{6,19,20}$ In addition, in mice, TSLP can act directly on T cells by inducing IL-4 production. ${ }^{15}$ Hence, we investigated whether DC-produced TSLP had an effect in the capacity of T cells to produce cytokines. BMDCs generated from femurs of C57/BL6 mice were activated or not with 

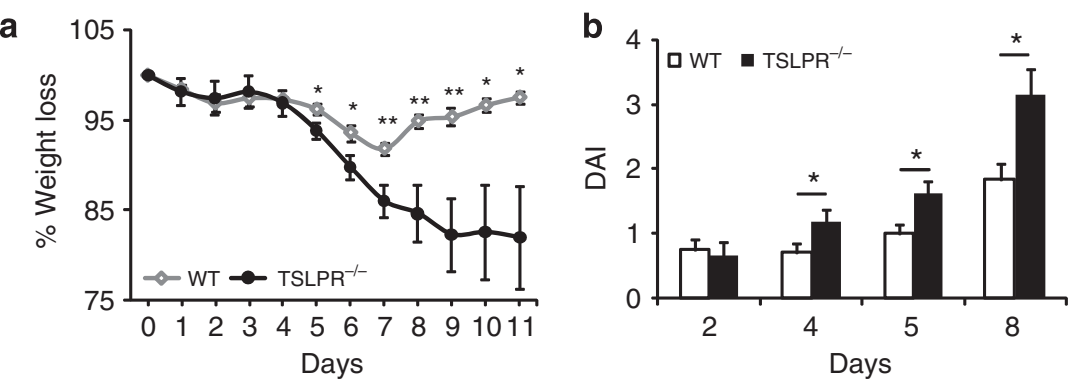

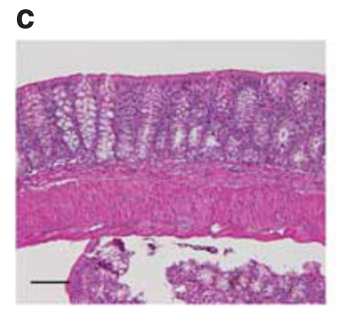

WT

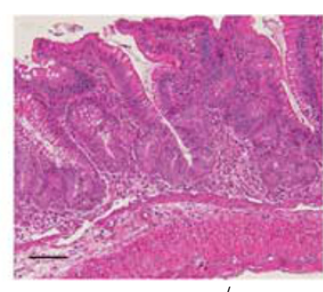

$\mathrm{TSLPR}^{-1-}$

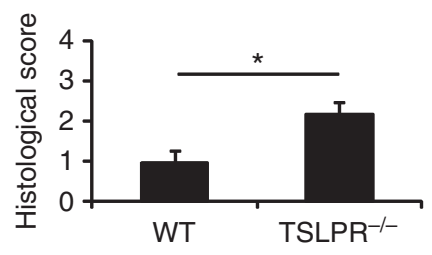

d
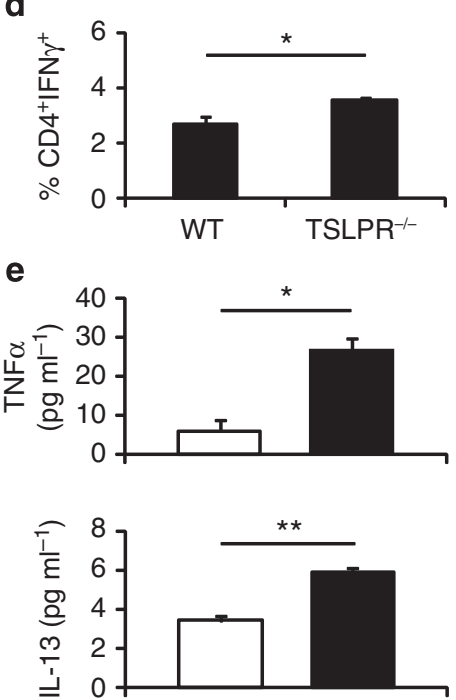
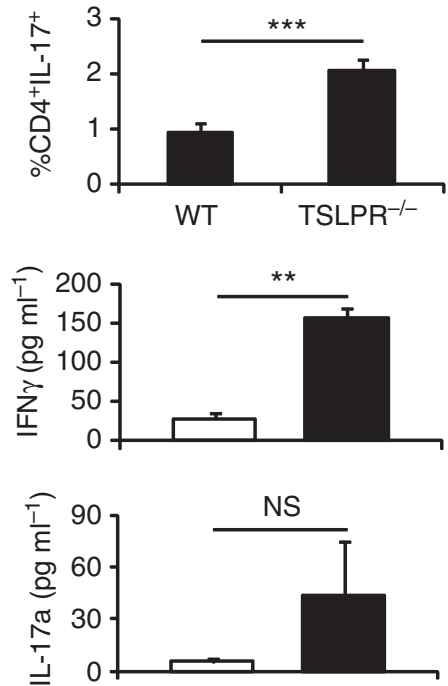

Figure 1 Thymic stromal lymphopoietin is required to protect against intestinal inflammation. Colitis was induced by adding $5 \%$ dextran sodium sulfate to drinking water for 7 days. Wild-type (WT) and TSLPR ${ }^{-1}$ mice were monitored for weight loss, stool consistency, and fecal occult blood. (a) Body weight loss. (b) Disease activity index (DAI). (c) Hematoxylin and eosin staining of paraffin-embedded colon sections. Original magnification $(\times 10)$ and scale bar $=200 \mu \mathrm{m}$. Colonic histology scores were assigned. (d) Mean percentages of colonic CD4 ${ }^{+} \mathrm{T}$ cells expressing interferon (IFN)- $\gamma$ and interleukin (IL)-17. (e) IL-17a, IFN- $\gamma$, IL-13 and tumor necrosis factor (TNF)- $\alpha$ concentration in the supernatants was tested by cytokine bead array. Error bars represent s.e.m. Results are representative of one of two experiments, each with five mice per group. ${ }^{\star} P<0.05,{ }^{\star \star} P<0.01,{ }^{\star \star \star} P<0.001$, NS: nonsignificant.

LPS and incubated with naïve T cells from TSLPR ${ }^{-1-}$ Balb/c mice in an allogeneic mixed leukocyte reaction. Intracellular cytokine staining was carried out on activated T cells while IL production in the culture medium was tested by cytokine bead array. We found that lack of TSLPR on T cells was associated to an increased differentiation of Th17 T cells in response to LPS-stimulated WT DCs as attested by intracellular cytokine staining (Figure 4a). We also found a reduced differentiation of $\mathrm{CD}^{+} \mathrm{T}$ cells expressing Foxp3 (Figure $4 \mathbf{b}$ ). This correlated with an increased production of protein and messenger RNA for IL-17A, and reduced release of IL-13 and IL-10 (Figure 5). We could not detect any differences in IFN- $\gamma$ release by $\mathrm{T}$ cells (Figure 5a), even though we had observed that non-treated DCs induced an increased percentage of IFN- $\gamma$-producing WT T cells as compared with TSLPR $^{-1-}$ T cells (Figure 4a). However, as WT T cells displayed a reduced mean fluorescence intensity of cytokine production as compared with TSLPR ${ }^{-1-} \mathrm{T}$ cells, it is likely that a lower number of cells with a higher expression may release a similar amount of IFN- $\gamma$ than a higher number of cells but at a lower expression. IL-4 was not induced after LPS stimulation and we could not detect much difference in T-cell cultures from TSLPR ${ }^{-1-}$ or WT mice (Figure 5). This suggests that in response to LPS, DC-derived TSLP does not skew Th2 T-cell polarization and this differs from the direct action of TSLP on $\mathrm{T}$ cells in the absence of other stimulations. ${ }^{15}$ Altogether, these results suggest that DC-produced TSLP acts on T cells by 
a

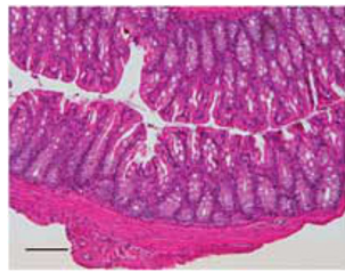

WT

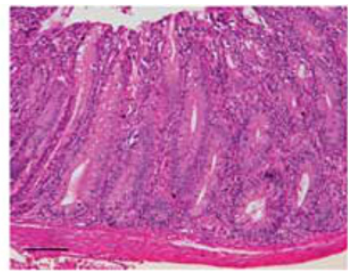

$\mathrm{TSLPR}^{-/-}$

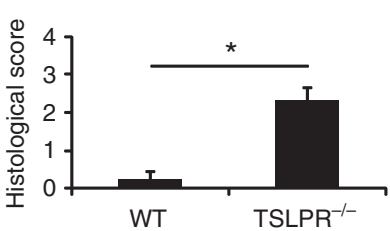

b
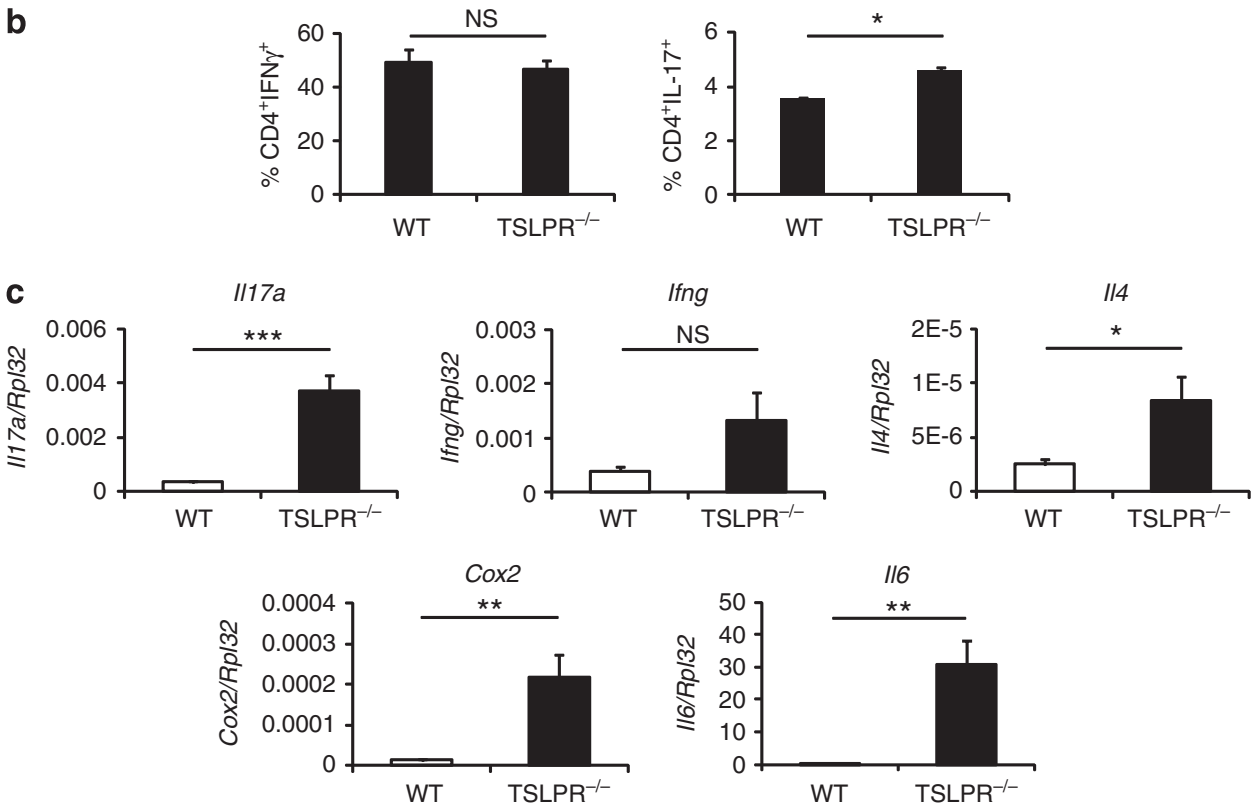

Figure 2 Thymic stromal lymphopoietin receptor (TSLPR) expression on T cells is required to protect against colitis. SCID mice were injected intraperitoneally with $4 \times 10^{5} \mathrm{CD} 4{ }^{+} \mathrm{CD} 25^{-} \mathrm{CD} 45 \mathrm{RB}^{\text {hi }} \mathrm{T}$ cells isolated from spleens of wild-type (WT) or TSLPR ${ }^{-/-}$BALB/c mice. Fifty days after T-cell adoptive transfer, mice were killed and analyzed for colitis development. (a) 5 - $\mu \mathrm{m}$ paraffin-embedded colon sections were stained with hematoxylin and eosin. Original magnification $\times 10$ and scale bar $=200 \mu \mathrm{m}$. Colonic histology scores were assigned. (b) Mean percentages of colonic CD4 ${ }^{+} \mathrm{T}$ cells expressing interferon (IFN)- $\gamma$ and interleukin (IL)-17. (c) $/ 117 a$, Ifn $\gamma$, II4, II6, and Cox2 gene expression was evaluated in colon samples by quantitative PCR. Each sample was normalized to Rp/32 gene. Error bars represent s.e.m. Results are representative of one of two experiments, each with five mice per group. ${ }^{\star} P<0.05,{ }^{\star \star} P<0.01,{ }^{* \star \star} P<0.001$, NS: nonsignificant.

limiting their differentiation to Th17, while fostering the development of Foxp3 ${ }^{+}$T cells.

TSLP acts directly on T cells to inhibit Th17 cell development As also DCs express the TSLPR, we could not exclude a possible autocrine effect of TSLP on DCs allowing then the T cells to respond to TSLP. Thus, we analyzed the effect of TSLP in T-cell polarization to Th17 in an antigen presenting cell-free assay. $\mathrm{TSLPR}^{-1-}$ and WT T cells were stimulated in vitro with anti$\mathrm{CD} 3 / \mathrm{CD} 28$ in the presence or absence of transforming growth factor (TGF)- $\beta$ and IL- 6 to promote or not Th17 differentiation, and cells were co-incubated with increasing doses of TSLP. Cytokine release was analyzed by cytokine bead array in 48 -h culture supernatants, while gene expression was evaluated by quantitative PCR on RNA extracted from T cells. As shown in Figure 6 and Supplementary Figure S3, Th17 differentiation was strongly affected by TSLP in a dose-dependent fashion, even though at the highest dose of $20 \mathrm{ng} \mathrm{ml}^{-1}$ the effect was less prominent. In agreement with previous data, ${ }^{15}$ the addition of TSLP in the absence of Th17-polarizing cytokines fostered the development of Th2 T-cell cytokines (IL-4, IL-5, and IL-13), but we could also observe an increase in IFN- $\gamma$ and IL-17 production (Figure 6). Together, these results suggest that TSLP induces Th2 and inhibits Th17 differentiation acting directly on $\mathrm{T}$ cells and not in an autocrine fashion on DCs.

\section{CD103+ DCs express TSLP in the gut}

In the gut, two populations of mononuclear phagocytes have been described that can be distinguished based on the expression of the $\alpha \mathrm{E}$ integrin CD103. ${ }^{29-31}$ It has been shown that $\mathrm{CD}_{103}{ }^{+} \mathrm{DCs}$ are capable to migrate to the mesenteric lymph node and to drive T-regulatory cell differentiation, ${ }^{32,33}$ while CD $103^{-}$cells resemble macrophages and are resident in the gut. ${ }^{34}$ Moreover, it has been described that CD103+ DCs isolated from colitic mice lose their tolerogenic properties and are capable to foster Th1 and Th17 T-cell differentiation. ${ }^{35}$ Hence, we first compared the level of expression of TSLP in cells isolated from intestinal tissues (colon): $\mathrm{CD}_{103}{ }^{+} \mathrm{DCs}, \mathrm{CD}_{103}{ }^{-}$mononuclear phagocytes, and epithelial cells. We found that $\mathrm{CD} 103^{+}$ DCs expressed twice as much TSLP than CD103- ${ }^{-}$phagocytes and nearly similar levels than epithelial cells (Supplementary Figure S4). We also observed that after DSS colitis while the 

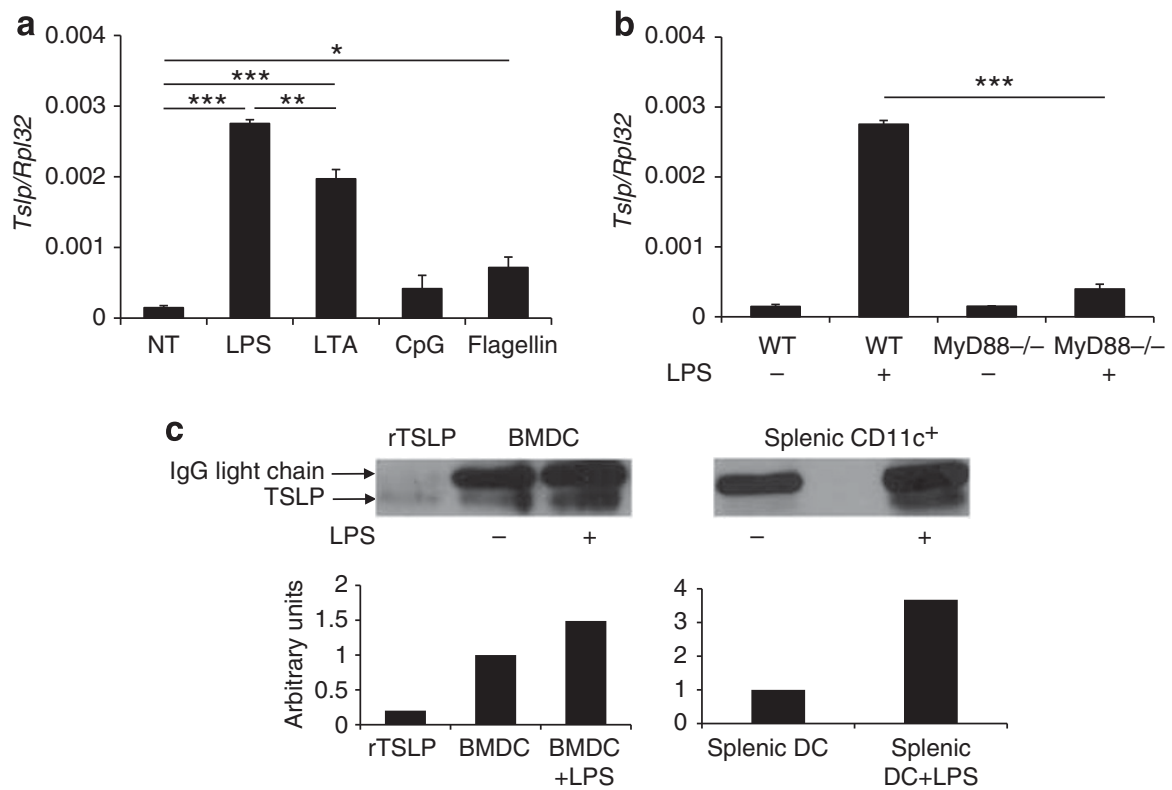

Figure 3 Mouse dendritic cells (DCs) express thymic stromal lymphopoietin (TSLP) after toll-like receptor engagement. (a, b) BMDCs were activated with $1 \mu \mathrm{g} \mathrm{ml}^{-1}$ lipopolysaccharide (LPS), $10 \mu \mathrm{g} \mathrm{ml}^{-1}$ lipotheicoic acid (LTA), $1 \mu \mathrm{moll}^{-1}-\mathrm{C}$-phosphate-G—(CpG), or $0.1 \mu \mathrm{g} \mathrm{ml} \mathrm{I}^{-1} \mathrm{flagellin}$ for $3 \mathrm{~h}$. Tslp gene expression was assayed in triplicate by quantitative real-time PCR. Each sample was normalized to Tbp expression. Results represent means \pm s.e.m. Data are representative from one of two independent experiments. ${ }^{\star} P<0.05,{ }^{\star \star} P<0.01,{ }^{\star \star \star} P<0.001$. (c) BMDCs were stimulated $3 \mathrm{~h}$ with LPS $\left(1 \mu \mathrm{g} \mathrm{ml}^{-1}\right)$ and for $4 \mathrm{~h}$ with PMA/ionomicine. Splenic CD11 $\mathrm{c}^{+} \mathrm{DCs}$ were isolated from mice $24 \mathrm{~h}$ after intravenous injection with LPS. TSLP was immunoprecipitated from total protein extracts. TSLP expression was detected by western blotting. Protein bands were quantified by densitometry and expressed relative to the untreated sample as arbitrary units. rTSLP, recombinant TSLP; NT, not treated; WT, wild-type.

a

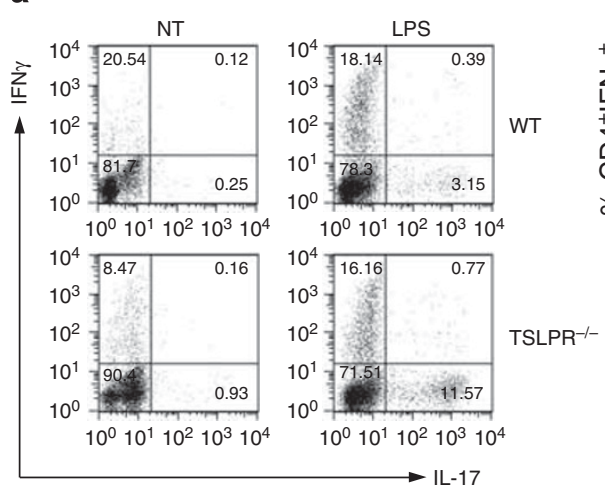

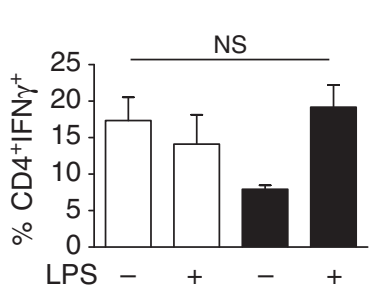

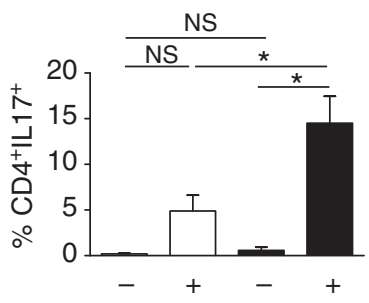

b

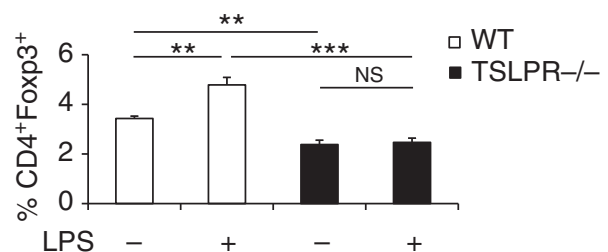

Figure 4 Dendritic cell-derived thymic stromal lymphopoietin (TSLP) controls Th17 and Treg cell differentiation. 2×104 BMDCs from C57BL/6J mice were activated or not with lipopolysaccharide (LPS). After washing, cells were cocultured with $10^{5} \mathrm{CD} 4^{+} \mathrm{CD} 25^{-} \mathrm{T}$ cells from spleens of wild-type (WT) or TSLPR ${ }^{-1-}$ BALB/c mice for 6 days. (a) Intracellular cytokine staining was carried out after 6 days of coculture. Left, representative dot plots showing percentages of interferon (IFN)- $\gamma^{+}$and interleukin (IL)- $17^{+}$T cells in the CD4 ${ }^{+}$gate. Right, frequencies of CD4 ${ }^{+} \mathrm{IFN}-\gamma^{+}$and $\mathrm{CD} 44^{+} \mathrm{IL}-17^{+}$ $T$ cells of three individual experiments are shown. Error bars represent s.e.m. (b) After 4 days, cells were stained for CD4 and Foxp3. Percentages of $\mathrm{CD} 4^{+}$Foxp3 ${ }^{+} \mathrm{T}$ cells are shown. Error bars represent s.e.m. of triplicate samples. Data are representative from one out of three independent experiments. ${ }^{\star} P<0.05,{ }^{\star \star} P<0.01,{ }^{\star * \star} P<0.001$. NS: nonsignificant.

expression of TSLP by CD103- cells remained unaltered, it was drastically reduced in $\mathrm{CD}_{103^{+}}{ }^{\mathrm{DC}}$ (Figure 7a). This seems to contradict the data that TSLP expression is induced by TLR ligation; however, it is known that lamina propria phagocytes (particularly macrophages, $\mathrm{CD}_{103}{ }^{-}$) are refractory to stimulation by most TLR ligands while $\mathrm{CD} 103^{+} \mathrm{DCs}$ already have a more activated phenotype. ${ }^{32,36,37}$ This may explain why $\mathrm{CD} 103^{-}$cells do not upregulate TSLP while CD $103^{+}$cells already express it.
We cannot explain why $\mathrm{CD} 103^{+} \mathrm{DC}$ downregulates TSLP in response to DSS. We then analyzed the role of TSLP expressed by $\mathrm{CD}_{103}{ }^{+} \mathrm{DCs}$ in T-cell activation. $\mathrm{CD}_{103}{ }^{+}$and $\mathrm{CD} 103^{-}$ DCs were isolated from mesenteric lymph nodes of C57/BL6 mice and incubated with naïve T cells from WT or TSLPR ${ }^{-1-}$ $\mathrm{Balb} / \mathrm{c}$ mice in an allogeneic mixed leukocyte reaction. The polarization of $\mathrm{T}$ cells toward Foxp $3^{+}$Treg, IL-17, or IFN- $\gamma$-producing $\mathrm{T}$ cells was evaluated by intracellular 

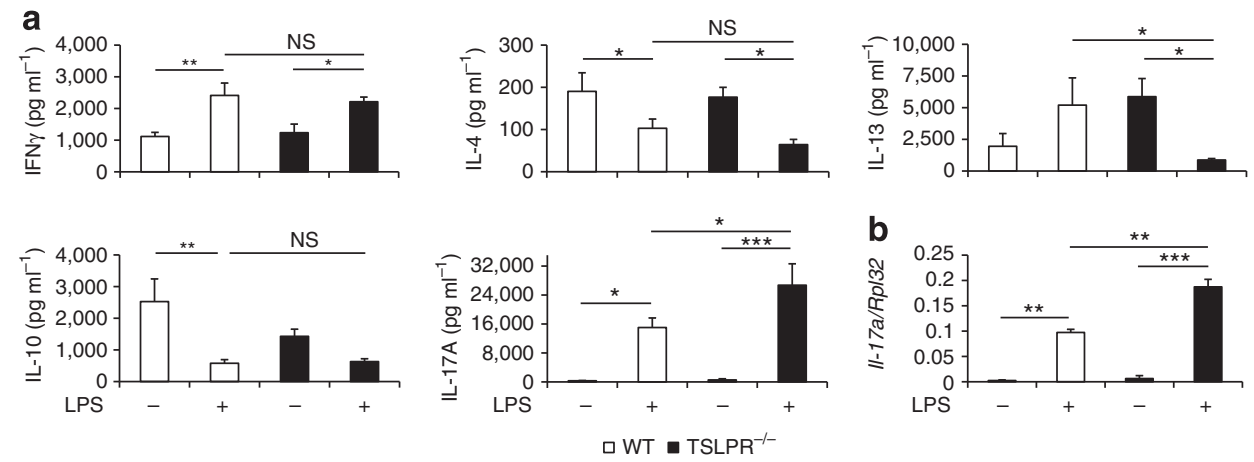

Figure 5 Lack of thymic stromal lymphopoietin receptor (TSLPR) on T cells is associated to an increased differentiation towards Th17. BMDCs generated from femurs of C57BL/6J mice were activated or not with lipopolysaccharide (LPS). These cells were cocultured with $\mathrm{CD}^{+} \mathrm{CD} 25^{-}$ T cells from spleens of wild-type (WT) or TSLPR ${ }^{-1-}$ BALB/c mice for 6 days. (a) Supernatants from the cocultures were harvested and cytokine concentrations were analyzed by cytokine bead array. Results represent means \pm S.e.m. Data represent three individual experiments. (b) II-17a gene expression was assayed by quantitative PCR. Each sample was normalized to Rp/32 expression. Results represent means \pm s.e.m. Data represent two independent experiments. ${ }^{\star} P<0.05,{ }^{\star \star} P<0.01,{ }^{* \star \star} P<0.001$. IFN, interferon; IL, interleukin; NS, nonsignificant.
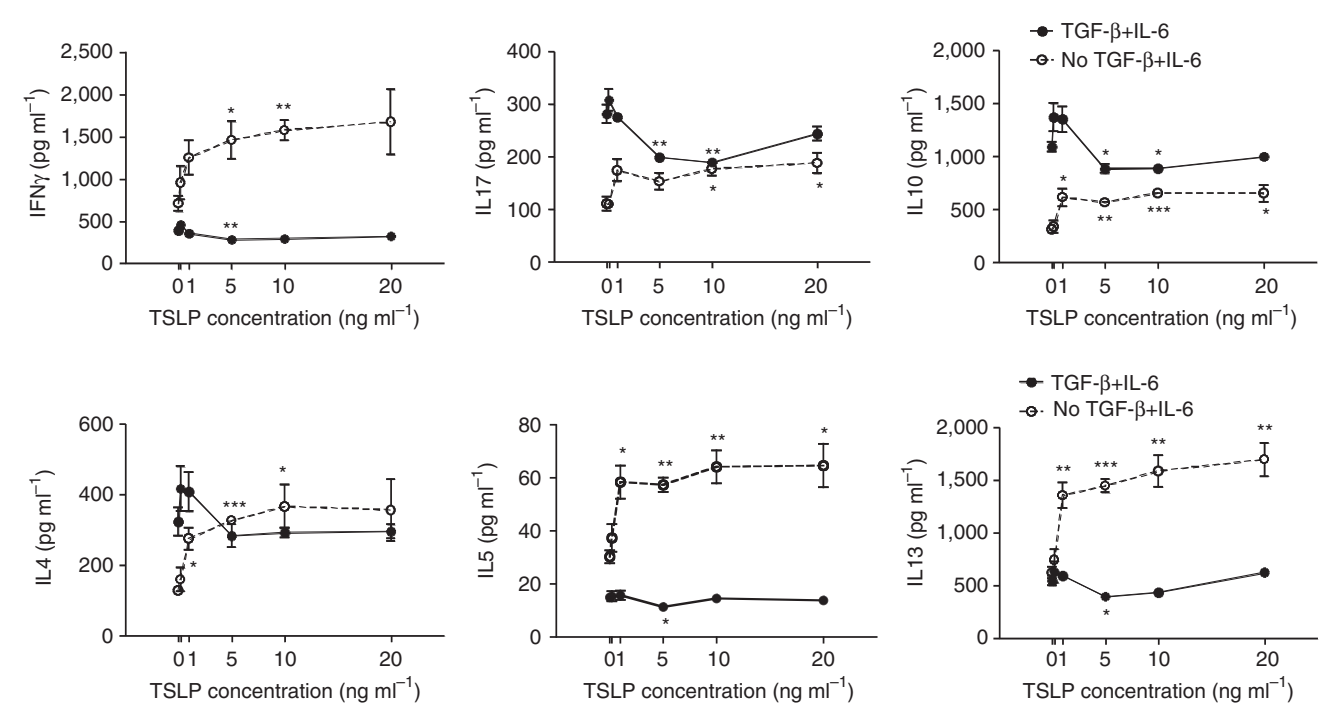

Figure 6 Thymic stromal lymphopoietin (TSLP) inhibits IL17 production in a dose-dependent manner. $2.5 \times 10^{5}$ mouse splenic CD4 ${ }^{+}$CD25- ${ }^{-}$cells were cultured in presence or absence of Th17-driving cytokines ( $5 \mathrm{ng} \mathrm{ml}^{-1}$ transforming growth factor (TGF)- $\beta 1$ and $20 \mathrm{ng} \mathrm{ml}^{-1}$ interleukin (IL)-6) with or without different concentrations of TSLP. The concentrations used were: $0.2,1,5,10$, or $20 \mathrm{ng} \mathrm{ml}^{-1}$. After $48 \mathrm{~h}$, supernatants from the cultures were harvested and cytokine production was measured by cytokine bead array. Results represent means \pm s.e.m. Data represent three independent experiments. ${ }^{\star} P<0.05,{ }^{* \star} P<0.01,{ }^{* \star *} P<0.001$. IFN, interferon.

cytokine staining. Consistent with a role of TSLP in fostering Treg cell development, we observed a drastic reduction in Treg differentiation by $\mathrm{CD} 103^{+}$DCs when $\mathrm{T}$ cells lacked TSLPR signaling (Figure 7b). No major differences were observed when stimulating with $\mathrm{CD}_{103^{-}}$cells. While we could not observe a significant difference in either IFN- $\gamma$ or IL-17 single producing $\mathrm{T}$ cells, we observed a significant increase in IFN- $\gamma / \mathrm{IL}-17$ double producing $\mathrm{TSLPR}^{-1-} \mathrm{T}$ effector cells after stimulation with $\mathrm{CD}_{103}{ }^{+}$DCs. This suggests that, in the absence of TSLP signaling, T cells are prone to differentiate more into inflammatory and less into regulatory cells.

\section{DISCUSSION}

Here, we have confirmed the very recent finding that DCs can produce the highly relevant cytokine $\mathrm{TSLP}^{27}$ that is involved in both physiological and pathological processes at mucosal surfaces and the skin. Our findings highlight an unanticipated function of TSLP in controlling intestinal homeostasis. DC-derived TSLP is important in regulating the development of Th17 and Treg cells acting directly on TSLPR expressed on T cells. This may be another feedback mechanism initiated by DCs to limit inflammation after TLR ligation. It has been recently shown that low doses of TSLP are capable of inhibiting de novo induction of Tregs without significantly promoting Th2 development; ${ }^{38}$ it is likely that DCs by upregulating TSLP after LPS triggering may skew towards Treg induction while limiting Th17 T-cell differentiation and thus constraint inflammation. By contrast, in the gut, $\mathrm{CD}_{103^{+}} \mathrm{DCs}$ already express higher levels of TSLP, promote Treg induction, and limit Th17 differentiation even in the absence of direct TLR stimulation. This has a physiological 

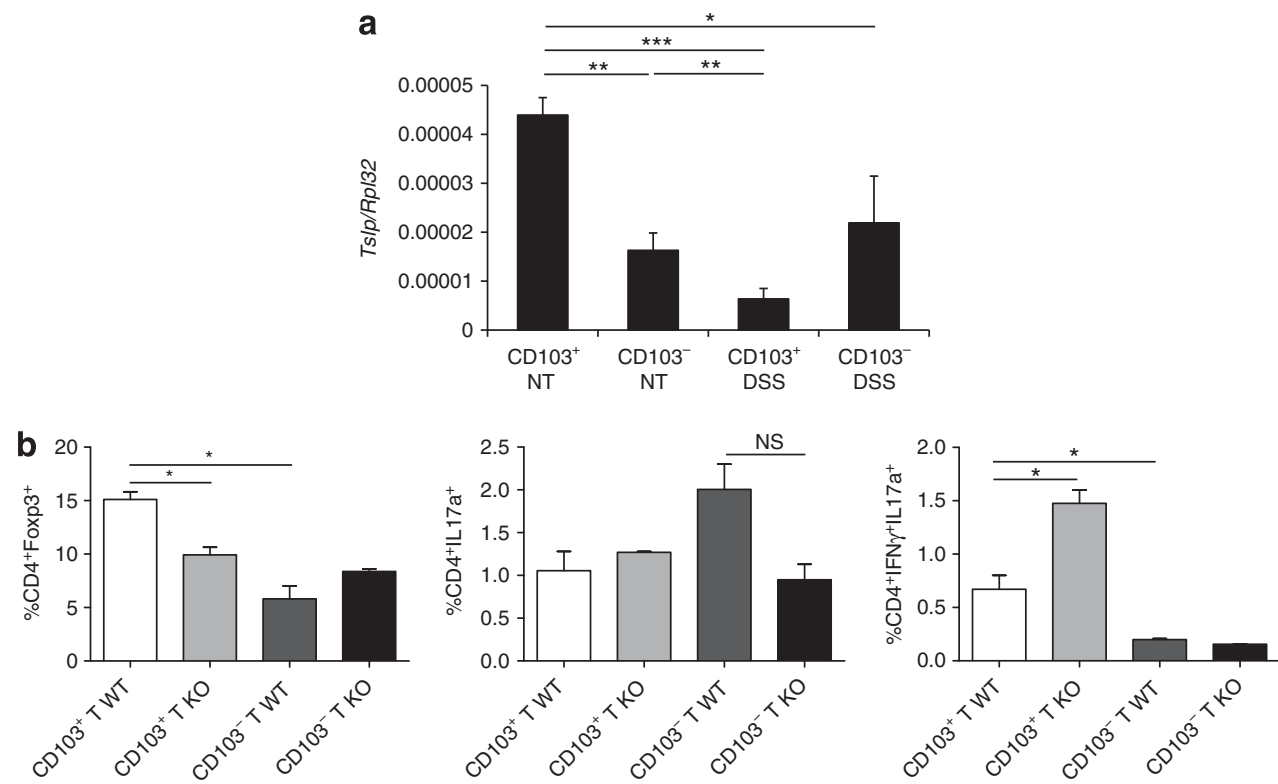

Figure 7 Colonic $\mathrm{CD}_{103^{+}}$dendritic cells (DCs) express thymic stromal lymphopoietin (TSLP). (a) $\mathrm{CD} 11 \mathrm{c}^{+} \mathrm{MHClI}^{+} \mathrm{CD} 103^{+}$and $\mathrm{CD} 11 \mathrm{C}^{+} \mathrm{MHClI}^{+} \mathrm{CD}_{103}-\mathrm{DC}$ populations were purified from colons of wild-type (WT) Balb/c mice treated or not with dextran sodium sulfate (DSS) for 7 days. Ts/p gene expression was assayed in the two DC subsets in triplicate by quantitative real-time PCR. Each sample was normalized to Rp/32 expression. (b) $\mathrm{CD}_{11 \mathrm{C}^{+} \mathrm{MHCII}}{ }^{+} \mathrm{CD} 103^{+}$and $\mathrm{CD} 11 \mathrm{c}^{+} \mathrm{MHCII}{ }^{+} \mathrm{CD} 103^{-} \mathrm{DC}$ populations were sorted from MLNs of WT C57BL/6J mice. These cells were cocultured with $\mathrm{CD} 4^{+} \mathrm{CD} 25^{-} \mathrm{T}$ cells from spleens of WT or TSLPR ${ }^{-/-} \mathrm{BALB} / \mathrm{c}$ mice for 6 days. Frequency of $\mathrm{CD} 4^{+} \mathrm{Foxp} 3^{+}, \mathrm{CD}^{+} \mathrm{IL}-17^{+}$, and $\mathrm{CD} 4{ }^{+}$IFN $-\gamma^{+} \mathrm{IL}-17^{+}$T cells is shown. Results represent means \pm s.e.m of two independent experiments. ${ }^{*} P<0.05,{ }^{\star \star} P<0.01,{ }^{\star \star \star} P<0.001$. IFN, interferon; IL, interleukin, KO, knockout.

role in protecting against inflammation as mice adoptively transferred with TSLPR ${ }^{-1-}$ T cells exhibit an increased susceptibility to experimental colitis and elevated Th17 T cells in the inflamed colons. We have not addressed here a possible autocrine role of TSLP on the DC themselves, which is likely to occur as TSLP can control the release of IL- 12 by DCs and limits the development of Th1 T cells. ${ }^{19,20}$ In fact, we have shown that TSLPR ${ }^{-/-}$mice are more susceptible to colitis and display increased levels of Th1 cytokines in the inflamed colons. Hence, it is possible that TSLP can act both on DCs by limiting their potential to drive Th1 T cells and on $\mathrm{T}$ cells by controlling their differentiation to Th2, Th17, and Tregs. In addition, TSLP has been shown to induce in an autocrine fashion the expression of secretory leukocyte peptidase inhibitor, an endogenous inhibitor of neutrophil elastase that has been shown to be required for the recovery phase after DSS treatment. ${ }^{26}$ Interestingly, after DSS-induced colitis, TSLP expression in $\mathrm{CD}_{103}{ }^{+}$DCs is drastically reduced while in $\mathrm{CD} 103^{-}$mononuclear phagocytic cells it is not upregulated. The reason for this is not known, but it may be due to the inability of lamina propria phagocytes to respond to ligation to most TLRs. ${ }^{37}$ We found that TSLP produced by $\mathrm{CD} 103^{+}$DCs is required for the differentiation of Foxp $3^{+}$Tregs and when T cells lack this signaling the differentiation of IL-17/IFN- $\gamma^{+} \mathrm{T}$ cells is fostered. Although the exact role of IL-17/IFN- $\gamma^{+}$T cells in the pathogenesis of colitis is not yet clear, it has been shown that these $\mathrm{T}$ cells express the IL-23R and accumulate in the lamina propria of patients with Crohn's disease. ${ }^{39}$ Interestingly, IL-23R signaling in T cells is involved in reducing the differentiation of Foxp3 ${ }^{+}$ Tregs and in the emergence of IL-17/IFN- $\gamma^{+}$T cells. ${ }^{40}$ It would be interesting to evaluate whether the cells that emerge in the absence of TSLPR signaling have upregulated the IL-23R. Our preliminary data indicate that TSLP is produced also by human DCs; thus, it would be interesting to evaluate whether in the human system DC-derived TSLP participates in limiting Th17 cell development and controlling intestinal inflammation.

Finally, in light of the recent findings that TSLP can be involved in the recruitment of basophils in response to T. muris infection ${ }^{41}$ or that TSLP is chemotactic for the DC themselves, ${ }^{42}$ DCs may mediate immune cell recruitment after their activation either in the periphery or draining lymph nodes, and thus further participate in the amplification of the immune response.

In conclusion, we have shown that DCs produce TSLP that can act directly on $\mathrm{T}$ cells by controlling their differentiation to Th17 and Tregs cells; this has important consequences on intestinal inflammation.

\section{METHODS}

Mice and cells. The 6-8-week-old WT C57BL/6J, BALB/c, and SCID mice were purchased from Harlan Laboratories (Milan, Italy). BALB/c TSLPR $^{-/-}$mice were provided by Dr W.J. Leonard (Laboratory of Molecular Immunology, NHLBI, USA). MyD $88^{-1-}$ mice were obtained by Dr S Akira (Osaka University, Japan). Mice were bred and maintained at IFOM-IEO Campus animal facility under specific pathogen-free conditions. All experiments were performed in accordance with the guidelines established in the Principles of Laboratory Animal Care (directive $86 / 609$ /EEC). Mode-k cells were kindly provided by Dr D. Kaiserlian. ${ }^{43}$

Isolation of DCs and endothelial cells from colonic lamina propria. Colon tissue was cut into small pieces and incubated in PBS containing $1 \%$ fetal bovine serum, 1-mM dithiothreitol, and 1-mM ethylene- 
diaminetetraacetic acid to remove epithelial cells. Epithelial cells were collected and stained with fluorescein isothiocyanate-conjugated CD45 (BD Biosciences, Bresso, MI, Italy) to exclude any possible hematopoietic contaminant during the fluorescence-activated cell sorting sorting (see below). Colonic tissue was further digested with complete minimum essential medium (MEM) Alpha (GIBCO, Invitrogen, Gaithersburg, MD) containing $5 \mathrm{U} \mathrm{ml}^{-1}$ DNase (Roche Diagnostic, Nutley, NJ) and $0.5 \mathrm{mg} \mathrm{ml}^{-1}$ collagenase type VIII (Sigma-Aldrich, Taufkirchen, Germany) for $30 \mathrm{~min}$ at $37^{\circ} \mathrm{C}$. Lamina propria (LP) cells were then layered on a $40 \% / 70 \%$ Percoll Plus gradient (GE Healthcare, Milan, Italy). Viable LP cells were collected at the $40 \% / 70 \%$ Percoll interface. LP cells were then stained with phycoerythrin-conjugated anti-CD103, PerCP Cy5.5-conjugated anti-CD11c, and antigen presenting cells-anti-MHCII (all purchased from BD Biosciences). $\mathrm{CD} 11 \mathrm{c}^{+} \mathrm{MHCII}{ }^{+} \mathrm{CD}_{103}{ }^{+}$and $\mathrm{CD}_{11 \mathrm{c}^{+} \mathrm{MHCII}}{ }^{+} \mathrm{CD} 103^{-} \mathrm{DC}$ populations and $\mathrm{CD} 45^{-}$cells were purified with FACSAria cell sorter (BD Biosciences).

Generation and activation of BMDCs. BMDCs were prepared from bone marrows of WT C57BL/6J and MyD88 $8^{-1-}$ mice, and cultured for 8 days in complete RPMI 1640 medium (GIBCO, Gaithersburg, MD) supplemented with 30\% supernatant from GM-CSF-producing NIH-3T3 cells. Mature BMDCs were activated with either $1 \mu \mathrm{g} \mathrm{ml}^{-1}$ LPS (SigmaAldrich) or $10 \mu \mathrm{g} \mathrm{ml}^{-1} \mathrm{LTA}$ (Sigma-Aldrich), $1 \mu \mathrm{moll}^{-1} \mathrm{CpG}$ (SigmaAldrich) or $0.1 \mu \mathrm{g} \mathrm{ml}^{-1}$ flagellin (Alexis Biochemicals, San Diego, CA) for $3 \mathrm{~h}$.

TSLP immunoprecipitation and western blot analysis. BMDCs were activated with $1 \mu \mathrm{g} \mathrm{ml}^{-1}$ LPS (Sigma-Aldrich) for $3 \mathrm{~h}$. Mice were injected intravenously with 20 - $\mu$ g ultrapure LPS (Invivogen, San Diego, CA). After $24 \mathrm{~h}$, splenic DCs were isolated by gentle digestion with collagenase D (Roche Diagnostic) and selection with anti-CD11c MACS beads (Miltenyi Biotec, Bergisch Gladbach, Germany). DCs were cultured for $4 \mathrm{~h}$ with $50 \mathrm{ng} \mathrm{ml}^{-1}$ phorbol 12-myristate 13-acetate (PMA, Sigma-Aldrich), $500 \mathrm{ng} \mathrm{ml}^{-1}$ ionomycin (Sigma-Aldrich), and Golgistop (BD Biosciences), and then lysed. TSLP protein was immunoprecipitated with anti-TSLP (R\&D Systems, Minneapolis, MN) from $200 \mu \mathrm{g}$ or $400 \mu \mathrm{g}$ of total protein extracts of BMDCs or spleen CD11 $\mathrm{c}^{+}$cells, respectively. Eluted proteins were loaded on 10\% SDS-PAGE, blotted on nitrocellulose filters, and proteins were detected using anti-TSLP (R\&D Systems). Band quantification was carried out using ImageJ software (Bethesda, MD).

RNA isolation and quantitation of gene expression by real-time PCR. Total RNA was purified from cells using RNeasy Kits (Qiagen, Hilden, Germany). Complementary DNA synthesis was performed using SuperScript III reverse transcriptase (Invitrogen) and random hexamers. Real-time PCR reactions were carried out using the SYBR Green
PCR kit and the primers listed in Table 1 on the Applied Biosystems 7500 Fast Real-Time PCR System (Applied Biosystems, Carlsbad, CA). Expression levels for each sample were normalized to the expression levels of Rpl32 or Tbp. Results were quantified using the $2^{-\Delta \Delta \mathrm{Ct}}$ method. ${ }^{44}$

Allogeneic DC/T-cell cocultures. A total of $2 \times 10^{4} \mathrm{BMDCs}$ from C57BL/6J mice, activated with LPS as previously described, or $2 \times 10^{4}$ DCs isolated from Mesenteric Lymph Nodes (MLNs), were cocultured for 6 days with $10^{5} \mathrm{CD} 4^{+} \mathrm{CD} 25^{-} \mathrm{T}$ cells purified according to manufacturer's instructions (Miltenyi Biotec) from spleens of WT or TSLPR ${ }^{-/-}$ $\mathrm{BALB} / \mathrm{c}$ mice. In some experiments, $2 \mathrm{ng} \mathrm{ml}^{-1}$ of human recombinant TGF- $\beta 1$ (R\&D Systems) was added at day 3 of coculture. After 4 days of culture, cells were stained for CD4 (BD Biosciences) and for Foxp3 (eBioscience, San Diego, CA) after permeabilization according to the manufacturer's protocol. At day 6, supernatants were collected and were analyzed for cytokines content using cytokine bead array Flex Set System (BD Biosciences). Cells from the cocultures were incubated with $50 \mathrm{ng} \mathrm{ml}^{-1} \mathrm{PMA}, 500 \mathrm{ng} \mathrm{ml}^{-1}$ ionomycin, and Golgistop for $4-5 \mathrm{~h}$. Lymphocytes were permeabilized using the Cytofix/Cytoperm Kit (BD Biosciences), and stained for CD4 (BD Biosciences), IFN- $\gamma$ (BD Biosciences), and IL-17 (BD Biosciences).

DSS-induced colitis. Colitis was induced by adding $5 \%$ (w/v) DSS (TdB Consultancy AB, Uppsala, Sweden) to drinking water for 7 days. Mice were monitored daily for weight loss, stool consistency, and fecal occult blood (Hemoccult, Beckman Coulter, Milan, Italy). Severity of colitis was evaluated measuring the disease activity index, which was calculated as previously described. ${ }^{45}$

T-cell transfer model of colitis. SCID mice were injected intraperitoneally with $4 \times 10^{5} \mathrm{CD} 4^{+} \mathrm{CD} 25^{-} \mathrm{CD} 45 \mathrm{RB}^{\text {hi }} \mathrm{T}$ cells isolated from spleens of WT or TSLPR ${ }^{-/-} \mathrm{BALB} / \mathrm{c}$ mice. In brief, enriched $\mathrm{CD} 4^{+}$singlecell suspensions were stained with phycoerythrin-conjugated antiCD4, antigen presenting cells-conjugated anti-CD25, and fluorescein isothiocyanate-anti-CD45RB (all purchased from BD Biosciences). Naïve CD ${ }^{+} \mathrm{CD} 25^{-} \mathrm{CD} 45 \mathrm{RB}{ }^{\text {hi }} \mathrm{T}$ cells were purified with a cell sorter (FACSAria, BD Biosciences). After T-cell reconstitution, mice were monitored for weight loss and for severe signs of colitis every 5 days. Mice were killed 50 days after T-cell adoptive transfer, and colon samples were immediately fixed in Hollandes Fixative (Polysciences, Eppelheim, Germany). The 5- $\mu \mathrm{m}$ paraffin-embedded colon sections were cut, and stained with hematoxylin and eosin. Inflammation was assessed in a blinded fashion.

Histology scoring system. The number of inflammatory cells (macrophages, lymphocytes, and plasma cells, and neutrophils) was evaluated by using a visual analogue scale modified for murine intestinal

Table 1 Primer table

\begin{tabular}{|c|c|c|}
\hline Gene & Sense $\left(5^{\prime}-3^{\prime}\right)$ & Antisense $\left(3^{\prime}-5^{\prime}\right)$ \\
\hline Rp/32 & AAGCGAAACTGGCGGAAAC & TAACCGATGTTGGGCATCAG \\
\hline$/ / 17 a$ & GGACTCTCCACCGCAATGA & GGCACTGAGCTTCCCAGATC \\
\hline$\| 17 f$ & CCCCATGGGATTACAACATCAC & CATTGATGCAGCCTGAGTGTCT \\
\hline 116 & CCATAGCTACCTGGAGTACATG & TGGAAATTGGGGTAGGAAGGAC \\
\hline Rorc & GGAGGACAGGGAGCCAAGTT & CCGTAGTGGATCCCAGATGACT \\
\hline $1 / 4$ & GGCATTTTGAACGAGGTCACA & GACGTTTGGCACATCCATCTC \\
\hline Cox2 & CCACTTCAAGGGAGTCTGGA & AGTCATCTGCTACGGGAGGA \\
\hline
\end{tabular}


specimens, and results were reported as the mean for the entire specimen. When considerable variation of intensity of infiltration was evident in the same specimen, the mean for several areas is determined and the specimen scored accordingly. Neutrophils and mononuclear cells were classified as absent (score 0 ) when there was none or only single sporadic cells per high-power field (HPF, using original magnification $\times 400$ ) ( $<5$ cells), mild (score 1 ) for a few cells (5-49 cells) per HPF, moderate (score 2) for several cells (50-99 cells) per HPF, and severe (score 3 ) for numerous cells (100-200 cells or more) per HPF. Histological criteria for normal or paraphysiological intestinal characteristics included detection of none or only a few mononuclear cells per HPF in perivascular area, and none or only a few scattered neutrophils interspersed throughout the mucosal corion without tissue changes (no sub-epithelial hyperemia or edema, and absence of any lymphoid aggregate, follicular in shape, in the lamina propria thickness; epithelial layer and glandular lumina/crypt free from exudate).

Quantitation of cytokine production in colonic tissues. Fresh colonic samples $(1 \mathrm{~cm})$ were cultured in RPMI 1640 supplemented with $100 \mathrm{U} \mathrm{ml}^{-1}$ penicillin, $100 \mu \mathrm{g} \mathrm{ml}^{-1}$ streptomycin, $100 \mu \mathrm{g} \mathrm{ml}^{-1}$ gentamicin, and $25 \mu \mathrm{g} \mathrm{ml}^{-1}$ amphotericin B for $24 \mathrm{~h}$. Frozen colonic tissues $(1 \mathrm{~cm})$ were homogenized in TRIzol (Invitrogen), and total RNA was precipitated according to manufacturer's instructions. To further purify RNA from tissues, RNeasy Mini Kit (Qiagen) was used. Complementary DNA synthesis and real-time PCR reactions were carried out as previously described. Samples were analyzed for the expression of Il17a, If $n \gamma$, Il4, Il6, and Cox2, using the primers listed in Table 1.

Isolation of lymphocytes from colonic LP and by fluorescenceactivated cell sorting analysis. Colon tissue was cut into small pieces and incubated in PBS containing $1 \%$ fetal bovine serum, $1 \mathrm{mM}$ dithiothreitol, and $1 \mathrm{mM}$ ethylenediaminetetraacetic acid to remove epithelial cells. Colonic tissue was further digested with complete MEM Alpha containing $5 \mathrm{U} \mathrm{ml}^{-1} \mathrm{DNase}$ and $0.5 \mathrm{mg} \mathrm{ml}^{-1}$ collagenase type VIII for $30 \mathrm{~min}$ at $37^{\circ} \mathrm{C}$. LP cells were then layered on a $40 \% / 70 \%$ Percoll Plus gradient and centrifuged for $20 \mathrm{~min}$ at 2000 r.p.m. Viable LP cells were collected at the $40 \% / 70 \%$ Percoll interface and incubated with $50 \mathrm{ng} \mathrm{ml}^{-1} \mathrm{PMA}, 500 \mathrm{ng} \mathrm{ml}^{-1}$ ionomycin, and Golgistop for $4-5 \mathrm{~h}$. Lymphocytes were then permeabilized using the Cytofix/Cytoperm Kit, and stained for CD4, IFN- $\gamma$, and IL- 17 .

In vitro Th17 polarization assay. The $2.5 \times 10^{5}$ mouse splenic $\mathrm{CD} 4^{+}$ CD25- ${ }^{-}$cells purified by magnetic separation (Miltenyi Biotec) were cultured in 48-well plates in complete RPMI 1640 in presence of $4 \mu \mathrm{g} \mathrm{ml}^{-1}$ plate-bound anti-CD3 and $4 \mu \mathrm{g} \mathrm{ml}^{-1}$ of soluble anti-CD28 alone or with $5 \mathrm{ng} \mathrm{ml}^{-1}$ human TGF- $\beta 1$ (R\&D Systems) and $20 \mathrm{ng} \mathrm{ml}^{-1}$ IL-6 (R\&D Systems). In some cultures, different concentrations of recombinant mouse TSLP (R\&D Systems) were added $(0.2,1,5,10$, and $20 \mathrm{ng} \mathrm{ml}^{-1}$ ). After $48 \mathrm{~h}$, culture medium was collected to measure IFN$\gamma$, IL-17a, IL-4, IL-5, IL-13 and IL-10 levels by cytokine bead array (BD Biosciences) while cells were harvested and RNA was extracted to evaluate cytokines gene expression.

Statistics. Results represent means \pm s.e.m. Statistical significance was determined by the Student's $t$ test using JMP 8.0 software (SAS, Cary, NC). ${ }^{\star} P<0.05,{ }^{\star *} P<0.01,{ }^{* *} P<0.001$.

SUPPLEMENTARY MATERIAL is linked to the online version of the paper at http://www.nature.com/mi

\section{ACKNOWLEDGMENTS}

This work was supported by the Crohn's and Colitis Foundation of America (CCFA to M.R.); Italian Association for Cancer Research (AIRC to $M . R$.); $7^{\text {th }}$ EU framework program to M.R. (IBDase, ERC: Dendroworld).

\section{DISCLOSURE}

The authors have no conflicts of interest.
() 2012 Society for Mucosal Immunology

\section{REFERENCES}

1. Friend, S.L., Hosier, S., Nelson, A., Foxworthe, D., Williams, D.E. \& Farr, A. A thymic stromal cell line supports in vitro development of surface lgM+B cells and produces a novel growth factor affecting $B$ and $T$ lineage cells. Exp. Hematol. 22, 321-328 (1994).

2. Al-Shami, A. et al. A role for thymic stromal lymphopoietin in CD4+ T cell development. J. Exp. Med. 200, 159-168 (2004).

3. Reche, P.A. et al. Human thymic stromal lymphopoietin preferentially stimulates myeloid cells. J. Immunol. 167, 336-343 (2001).

4. Lee, H.C. \& Ziegler, S.F. Inducible expression of the proallergic cytokine thymic stromal lymphopoietin in airway epithelial cells is controlled by NFkappaB. Proc. Natl. Acad. Sci. USA 104, 914-919 (2007).

5. Ziegler, S.F. \& Artis, D. Sensing the outside world: TSLP regulates barrier immunity. Nat. Immunol. 11, 289-293 (2010).

6. Soumelis, V. et al. Human epithelial cells trigger dendritic cell mediated allergic inflammation by producing TSLP. Nat. Immunol. 3, 673-680 (2002).

7. Kato, A., Favoreto, S. Jr., Avila, P.C. \& Schleimer, R.P. TLR3- and Th2 cytokine-dependent production of thymic stromal lymphopoietin in human airway epithelial cells. J. Immunol. 179, 1080-1087 (2007).

8. Ying, S. et al. Thymic stromal lymphopoietin expression is increased in asthmatic airways and correlates with expression of Th2-attracting chemokines and disease severity. J. Immunol. 174, 8183-8190 (2005).

9. De Monte, L. et al. Intratumor T helper type 2 cell infiltrate correlates with cancer-associated fibroblast thymic stromal lymphopoietin production and reduced survival in pancreatic cancer. J. Exp. Med. 208, 469-478 (2011).

10. Pedroza-Gonzalez, A. et al. Thymic stromal lymphopoietin fosters human breast tumor growth by promoting type 2 inflammation. J. Exp. Med. 208, 479-490 (2011).

11. Yoo, J. et al. Spontaneous atopic dermatitis in mice expressing an inducible thymic stromal lymphopoietin transgene specifically in the skin. J. Exp. Med. 202, 541-549 (2005).

12. Zhou, B. et al. Thymic stromal lymphopoietin as a key initiator of allergic airway inflammation in mice. Nat. Immunol. 6, 1047-1053 (2005).

13. He, R., Oyoshi, M.K., Garibyan, L., Kumar, L., Ziegler, S.F. \& Geha, R.S. TSLP acts on infiltrating effector $T$ cells to drive allergic skin inflammation. Proc. Natl. Acad. Sci. USA 105, 11875-11880 (2008).

14. Pandey, A. et al. Cloning of a receptor subunit required for signaling by thymic stromal lymphopoietin. Nat. Immunol. 1, 59-64 (2000).

15. Omori, M. \& Ziegler, S. Induction of IL-4 expression in CD4(+) T cells by thymic stromal lymphopoietin. J. Immunol. 178, 1396-1404 (2007).

16. Lu, N., Wang, Y.H., Arima, K., Hanabuchi, S. \& Liu, Y.J. TSLP and IL-7 use two different mechanisms to regulate human $\mathrm{CD} 4+\mathrm{T}$ cell homeostasis. J. Exp. Med. 206, 2111-2119 (2009).

17. Rochman, I., Watanabe, N., Arima, K., Liu, Y.J. \& Leonard, W.J. Cutting edge: direct action of thymic stromal lymphopoietin on activated human CD4+ T cells. J. Immunol. 178, 6720-6724 (2007).

18. Taylor, B.C. et al. TSLP regulates intestinal immunity and inflammation in mouse models of helminth infection and colitis. J. Exp. Med. 206, 655-667 (2009).

19. Zaph, C. et al. Epithelial-cell-intrinsic IKK-beta expression regulates intestinal immune homeostasis. Nature 446, 552-556 (2007).

20. Rimoldi, M. et al. Intestinal immune homeostasis is regulated by the crosstalk between epithelial cells and dendritic cells. Nat. Immunol. 6, 507-514 (2005).

21. Mileti, E., Matteoli, G., lliev, I.D. \& Rescigno, M. Comparison of the immunomodulatory properties of three probiotic strains of Lactobacilli using complex culture systems: prediction for in vivo efficacy. PLoS One 4, e7056 (2009).

22. Zeuthen, L.H., Fink, L.N. \& Frokiaer, H. Epithelial cells prime the immune response to an array of gut-derived commensals towards a tolerogenic phenotype through distinct actions of thymic stromal lymphopoietin and transforming growth factor-beta. Immunology 123, 197-208 (2008).

23. Iliev, I.D., Mileti, E., Matteoli, G., Chieppa, M. \& Rescigno, M. Intestinal epithelial cells promote colitis-protective regulatory T-cell differentiation through dendritic cell conditioning. Mucosal Immunol. 2, 340-350 (2009). 
24. Iliev, I.D. et al. Human intestinal epithelial cells promote the differentiation of tolerogenic dendritic cells. Gut 58, 1481-1489 (2009).

25. Hanabuchi, S. et al. Thymic stromal lymphopoietin-activated plasmacytoid dendritic cells induce the generation of FOXP3+ regulatory T cells in human thymus. J. Immunol. 184, 2999-3007 (2010).

26. Reardon, C. et al. Thymic stromal lymphopoetin-induced expression of the endogenous inhibitory enzyme SLPI mediates recovery from colonic inflammation. Immunity 35, 223-235 (2011).

27. Kashyap, M., Rochman, Y., Spolski, R., Samsel, L. \& Leonard, W.J. Thymic stromal lymphopoietin is produced by dendritic cells. J. Immunol. 187, 1207-1211 (2011)

28. Kawai, T. \& Akira, S. TLR signaling. Semin. Immunol. 19, 24-32 (2007).

29. Coombes, J.L. \& Powrie, F. Dendritic cells in intestinal immune regulation. Nat. Rev. Immunol. 8, 435-446 (2008).

30. Rescigno, M. \& Di Sabatino, A. Dendritic cells in intestinal homeostasis and disease. J. Clin. Invest. 119, 2441-2450 (2009).

31. Pabst, O. \& Bernhardt, G. The puzzle of intestinal lamina propria dendritic cells and macrophages. Eur. J. Immunol. 40, 2107-2111 (2010)

32. Sun, C.M. et al. Small intestine lamina propria dendritic cells promote de novo generation of Foxp3T reg cells via retinoic acid. J. Exp. Med. 204 1775-1785 (2007).

33. Coombes, J.L. et al. A functionally specialized population of mucosal CD103+ DCs induces Foxp3+ regulatory T cells via a TGF- $\backslash\{$ beta $\backslash\}$ and retinoic acid depend. J. Exp. Med. 204, 1757-1764 (2007).

34. Schulz, O. et al. Intestinal CD103+, but not CX3CR1+, antigen sampling cells migrate in lymph and serve classical dendritic cell functions. J. Exp. Med. 206, 3101-3114 (2009).

35. Laffont, S., Siddiqui, K.R. \& Powrie, F. Intestinal inflammation abrogates the tolerogenic properties of $\mathrm{mln}$ cd103(+) dendritic cells. Eur. J. Immunol. 40, 1877-1883 (2010)
36. Smythies, L.E. et al. Human intestinal macrophages display profound inflammatory anergy despite avid phagocytic and bacteriocidal activity. J. Clin. Invest. 115, 66-75 (2005).

37. Monteleone, I., Platt, A.M., Jaensson, E., Agace, W.W. \& Mowat, A.M. IL-10-dependent partial refractoriness to Toll-like receptor stimulation modulates gut mucosal dendritic cell function. Eur. J. Immunol. 38, 1533-1547 (2008)

38. Lei, L., Zhang, Y., Yao, W., Kaplan, M.H. \& Zhou, B. Thymic stromal lymphopoietin interferes with airway tolerance by suppressing the generation of antigen-specific regulatory T cells. J. Immunol. 186, 2254-2261 (2011)

39. Kleinschek, M.A. et al. Circulating and gut-resident human Th17 cells express CD161 and promote intestinal inflammation. J. Exp. Med. 206, 525-534 (2009).

40. Ahern, P.P. et al. Interleukin-23 drives intestinal inflammation through direct activity on T cells. Immunity 33, 279-288 (2010).

41. Perrigoue, J.G. et al. MHC class II-dependent basophil-CD4+ T cell interactions promote $\mathrm{T}(\mathrm{H}) 2$ cytokine-dependent immunity. Nat. Immunol. 10, 697-705 (2009).

42. Fernandez, M.I. et al. The human cytokine TSLP triggers a cellautonomous dendritic cell migration in confined environments. Blood 118, 3862-3869 (2011)

43. Vidal, K., Grosjean, I., evillard, J.P., Gespach, C. \& Kaiserlian, D. Immortalization of mouse intestinal epithelial cells by the SV40-large T gene. Phenotypic and immune characterization of the MODE-K cell line. J. Immunol. Methods 166, 63-73 (1993).

44. Pfaffl, M.W. A new mathematical model for relative quantification in real-time RT-PCR. Nucleic Acids Res. 29, e45 (2001).

45. Cooper, H.S., Murthy, S.N., Shah, R.S. \& Sedergran, D.J. Clinicopathologic study of dextran sulfate sodium experimental murine colitis. Lab. Invest. 69, 238-249 (1993). 